\title{
The oldest isorophid edrioasteroid (Echinodermata) and the evolution of attachment strategies in Cambrian edrioasteroids
}

Samuel Zamora and Andrew B. Smith

Acta Palaeontologica Polonica 55 (3), 2010: 487-494 doi: http://dx.doi.org/10.4202/app.2010.0012

Two new middle Cambrian edrioasteroid (Echinodermata), Protorophus hispanicus gen. et sp. nov., and Isorophida gen. et sp. indet., are described from the early middle Cambrian (Cambrian Series 3, Stage 5) of Spain. These are the oldest and probably the most primitive isorophids, a clade previously known from the upper Cambrian onwards. Specimens are attached to trilobite fragments indicating that edrioasteroids had by this time separated into two lineages each with different strategies for attachment, sediment attachers and hard substrate attachers. The single U-shaped ambulacral flooring plates of Protorophus are unique while Isorophida gen. et sp. indet. shares the presence of spines in common with some pyrgocystitid isorophids. The shift from facultative soft-bottom attachment to obligate hard-ground attachment in edrioasteroids involved the retention of a juvenile trait into adulthood and was already underway by the middle Cambrian.

Key words: Echinodermata, Cambrian, Isorophida, edrioasteroid, Cambrian, Spain.

Samuel Zamora [samuel@unizar.es], Área y Museo de Paleontología-IUCA, Departamento de Ciencias de la Tierra, Universidad de Zaragoza, E-50009 Zaragoza, Spain; Andrew B. Smith [a.smith@nhm.ac.uk], Department of Palaeontology, The Natural History Museum, Cromwell Road, London SW7 5BD, UK.

This is an open-access article distributed under the terms of the Creative Commons Attribution License (for details please see creativecommons.org), which permits unrestricted use, distribution, and reproduction in any medium, provided the original author and source are credited. 
FoF Full text $(620.9 \mathrm{kB})$ 